\title{
Sticky Tales
}

\section{Spiders, Silk, and Human Attachments}

\author{
Eleanor Morgan, University College London
}

Every AUTUMn I AM OVERRUn WITH SPIDERs. More specifically, female orb-weaving spiders. During the gossamer days of September and October, their webs seem to cover every tree, bush, and railing. It is the glint of these webs that first attracted me, as it has attracted so many other spider enthusiasts - the seductive glance of spider's silk, created by a creature more likely to instil in us fear than attraction.

Humans have collected spider's silk for centuries. Women in Bermuda used it for sewing, communities in the South Pacific used it to make fishing nets and lines, and since the time of the Ancient Greeks, spider webs have been used to help heal wounds - a possibility that is still being explored today in biomedical research using artificial silk. Yet unlike silkworms, spiders have resisted all attempts at large-scale harvesting. Even recent research into artificial silk has been unable to replicate the mysterious transformation of liquid protein to solid silk that takes place in the body of the spider.

As part of my art practice I collect and weave with spider's silk and I investigate the history of our mythological and material connections with spiders. In the autumn of 2010, my research took me to the east coast of the United States to explore two tales of human-spider attachments and 
to create videos, sculptures, and drawings. This paper describes my work in progress stemming from this trip. It is part artist's journal, part historical research, tracing two sticky tales of spiders, silk, and the people who are drawn to them. Both are stories on and around circles. In the first tale, I recreate a soldier's ring - a golden band of silk. In the second, a spider crosses the inside of a telescope tube, leaving a trail of silk that alters forever how astronomers measure the stars, and how soldiers measure their enemies.

\section{Tale One: Folly Island and the Golden Ring}

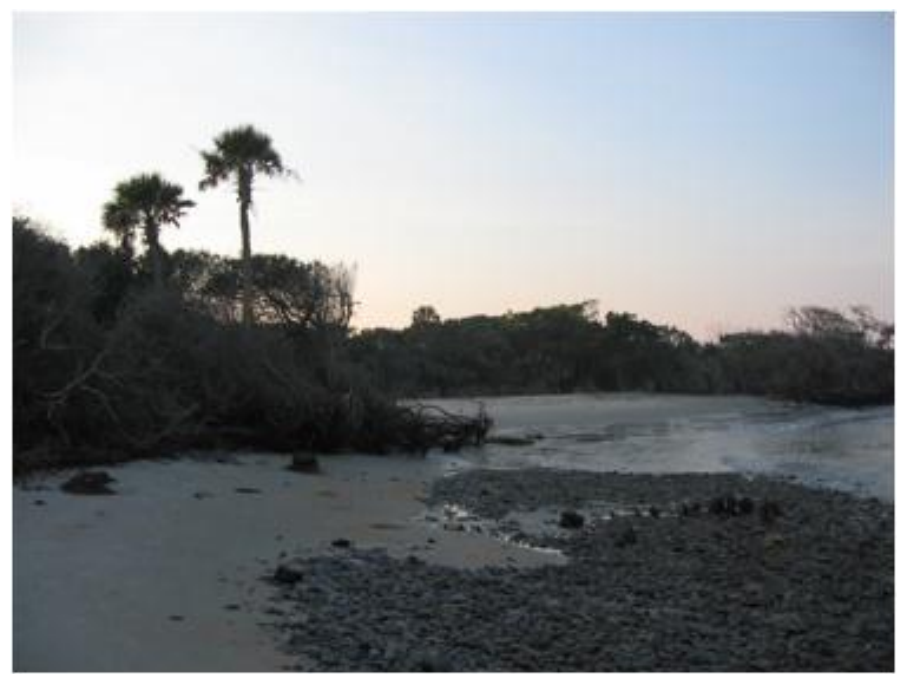

Fig 1. Folly Island.

Folly Island is a sandbar on the east coast of the United States. Once a convenient site for ships to offload their dead and dying before landing on the mainland, the island is now a popular resort for tourists and surfers. I was on Folly to look for a certain species of spider, whose ancestors played a part in the lives of two soldiers during the American civil war.

In 1863, a Union Army surgeon in the 55th Massachusetts regiment named Dr Burt Green Wilder was stationed on Folly Island. To pass the time he would explore its forested terrain, and it was on one of these walks that he discovered a huge spider sitting in the centre of a golden coloured web, which stretched 10 feet between the trees. He collected the spider in his hat and carried it back to his tent. Here, he describes the scene:

The insect was very quiet, and did not attempt to escape; but presently, after crawling slowly along my sleeve, she let herself down to the floor, taking first the precaution, after the prudent fashion of most spiders, to attach to the point she left a silken line, which, as she descended, came from her body. Rather than seize the insect itself, I caught the thread and pulled. The spider was not moved, but the line readily drew out, and, being 
wound upon my hands, seemed so strong that I attached the end to a little quill, and, having placed the spider upon the side of the tent, lay down on my couch and turned the quill between my fingers. ${ }^{1}$

He continued at this for an hour and a half, after which time he had collected over one hundred and fifty yards of 'the most brilliant and beautiful golden silk I had ever seen'. The spider that Wilder had found was the Nephila, or golden orb spider.

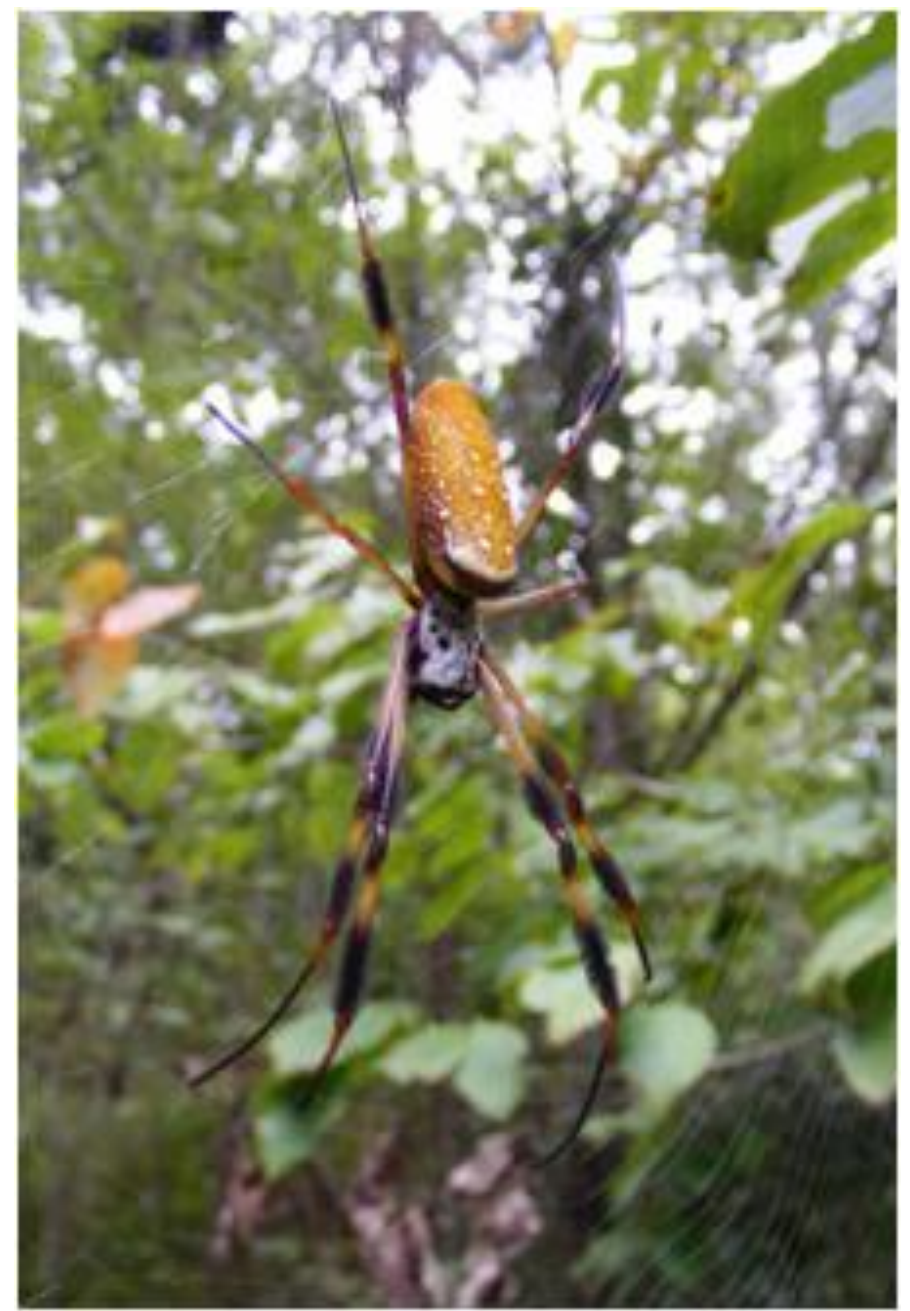

Fig. 2. The golden orb spider.

The golden orb is a large orb-weaving spider that gets its name from the golden colour of its silk. It produces one of the strongest of all spider's silks. In addition, the females are much larger than the males. This size discrepancy is true for most spiders, but is particularly noticeable in the golden orb spider. The male is so small that he can live on the female's web, and even mate with her, without her noticing.

$A$ video describing spider mating is available in the HTML version of this article. 
Wilder began experimenting with various ways to wind the silk from the spider. He created a machine in which the spider was held in place upside down, which gave easier access to the spinnerets and was apparently more comfortable for the spider.

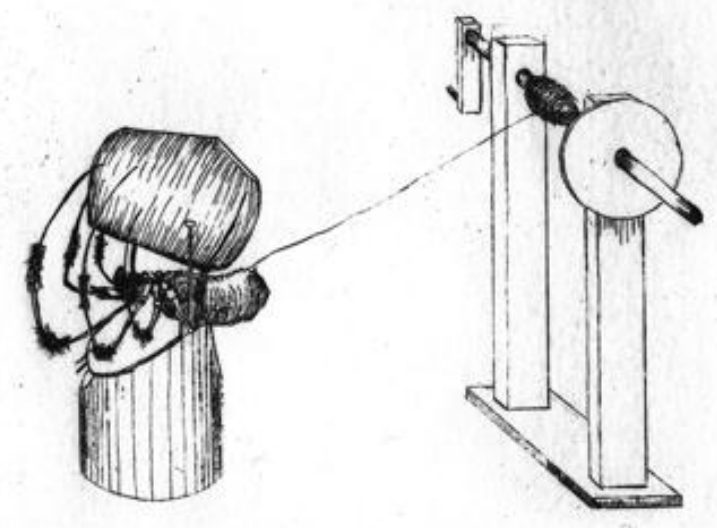

Fig. 3. Burt Wilder’s spider spinning machine.

In the autumn of 1864, Wilder was able to wind almost two miles of golden silk on this machine. However, the silk was too thin to weave. So he devised a machine in which the threads could be twisted together into a thicker strand.

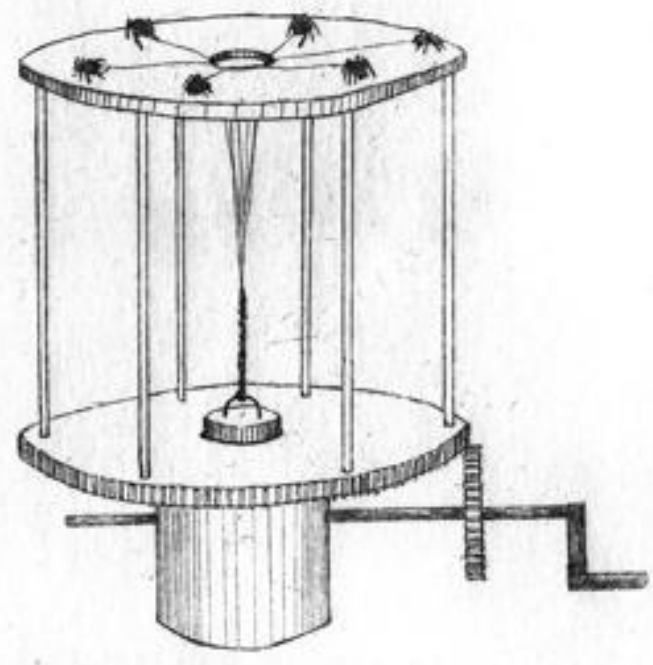

Fig. 4. Burt Wilder's second spider spinning machine (author's etching from Wilder's description) 
The bottom plate of this machine was stationary, so as Wilder turned the handle the silk strands coming from the spider's spinnerets would wind together. He had some problems with this machine; with so many spiders in close contact, they had a tendency to eat each other.

Wilder was not the only soldier on Folly Island to have discovered this spider. Sigourney Wales, a lieutenant in the same regiment, had been passing the long hours on lookout duty by carving trinkets and mementoes, which he sold to the other men.

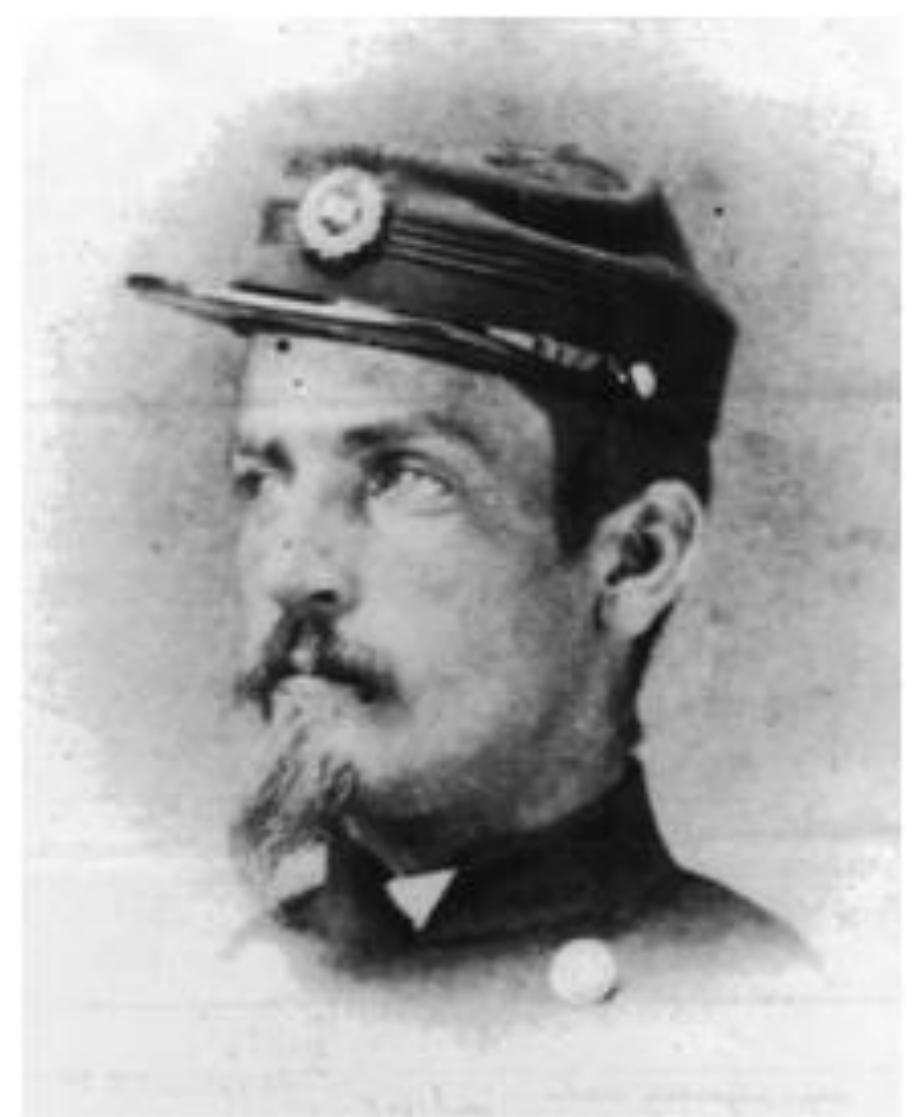

Fig. 5. Lieutenant Sigourney Wales. Credit: Army Military Institute.

He came across the golden orb spider, and, like Wilder, realized that he could pull silk directly from the spider's spinnerets. He attached the thread to a spool and wound the yellow silk onto rings, which apparently he was able to sell as real gold jewellery.

I wanted to recreate this spider jewellery-making machine. While exploring Folly, I had found five female golden orb spiders in a forested area to the north of the island. Their webs were huge and golden; some stretched across the footpaths, so that it was easy to accidentally walk into them. If I did, the female at the centre would shake vigorously on the web, so fast that she would appear as a blur. The spiders themselves can grow almost to the size of a human hand, but can move with a delicate touch - stretching out their long front legs to detect vibrations. 
I created my spider silk spinning machine from bits of left over wood, metal and broken tools. At the centre of the spool was a rubber ring on which, as with Wales's machine, I wound the golden silk of the spider.

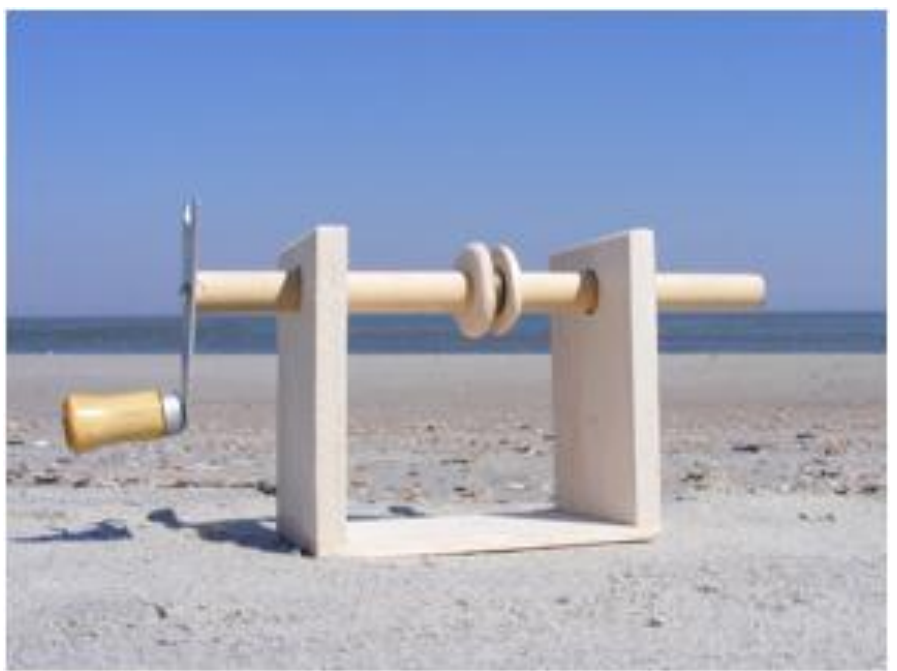

Fig. 6. Spinning machine.

There were so many disused webs and strands of silk hanging from the trees, that it was not necessary to pull the silk from the spider's bodies. Instead I wrapped the discarded silk around the ring, and wound and wound. The silk was so strong, almost like cotton in some places, that I could not break it with my hands. Instead, I put my mouth to the silk and bit it.

A video of the spinning machine is available in the HTML version of this article.

After days of spinning, I had made a golden ring of spider's silk.

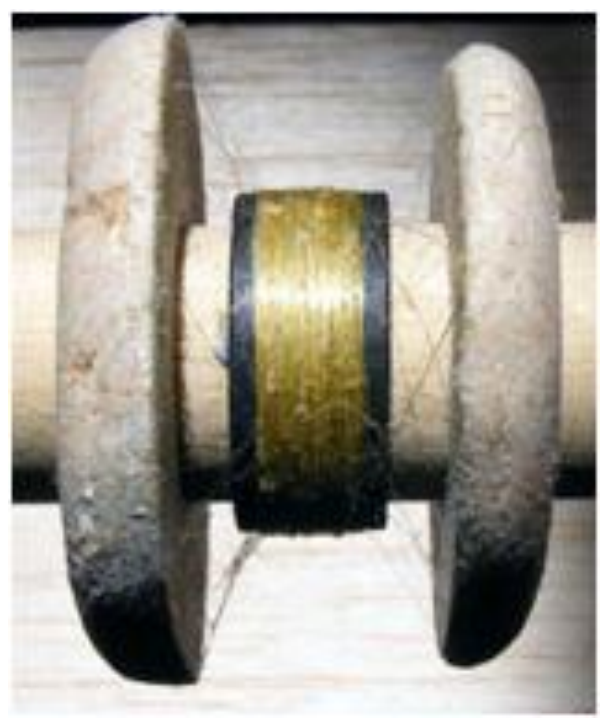

Fig. 7. Ring of spider's silk. 


\section{Tale Two: Cross Hairs and Optical Instruments}

In 1639, the English astronomer William Gascoigne woke to find that a spider had spun a web inside his telescope. ${ }^{2} \underline{2}$ He looked down the eyepiece and saw that the strands of silk were clearly visible, but thin and transparent enough not to obscure the stars that he was watching. The spider had magically spun its web at the common focal plane. As such, Gascoigne was able to see both the silk and the stars in perfect focus.

Over the following two centuries a number of astronomers and surveyors independently discovered the use of spider's silk as an ideal material for making in the crosshairs of optical instruments. Other materials had been tried, such as human hair, silkworm silk, and platinum wires, but they were either too wide or not straight enough to allow a clear view of the stars or accurate measurement. The qualities of spider's silk - its thinness, strength, stretch, ability to sustain low temperatures and durability in water - made it the perfect material for such a job.

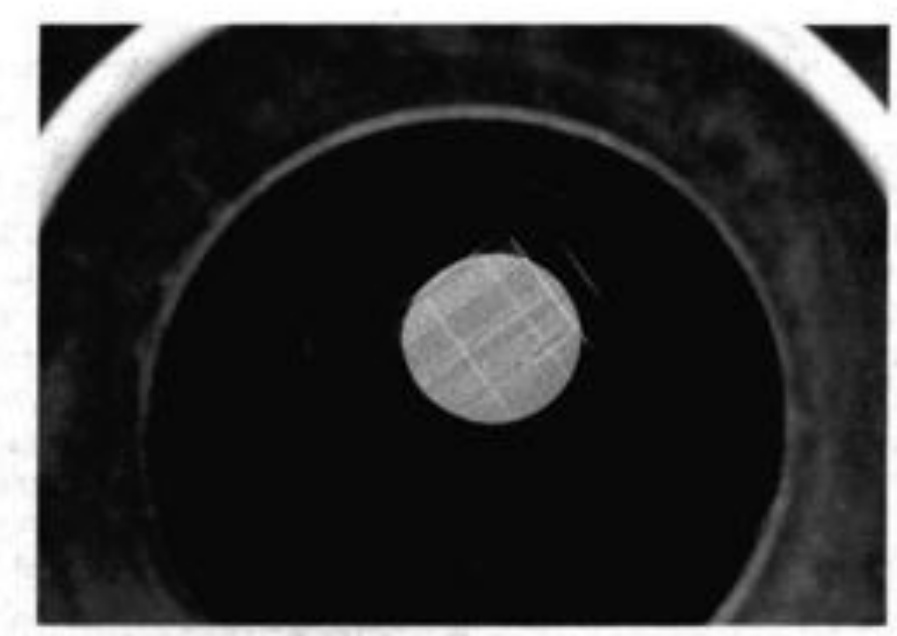

Fig. 8. Spider's silk cross lines in a transit micrometer. Credit: National Museum of American History, Smithsonian Institution, Washington DC.

By the mid-nineteenth century most optical instrument makers in England had adopted the use of spider's silk in crosshairs, giving both improved precision and focus to the measurement of the stars and of the land. The increased demand for spider's silk created new career opportunities. In 1889 a fourteen-year-old girl named Mary Pfeiffer became the first recorded full-time silk collector. Known as the 'Spider lady', she was employed by the optical instrument makers Keuffel \& Esser and remained working there for over 50 years. She would scour the local pigsties of New Jersey looking for spiders, which she would collect and take back to her office. There, she allowed them to move freely around her. When one began to spin, she would use a small wooden 
frame to reel in its silk. Each year she collected over 2000 feet of web, which could be stored and delivered across the country.

Here is the only image I have found of her - printed in a newspaper article from 1915 reporting a worrying moment for the company:

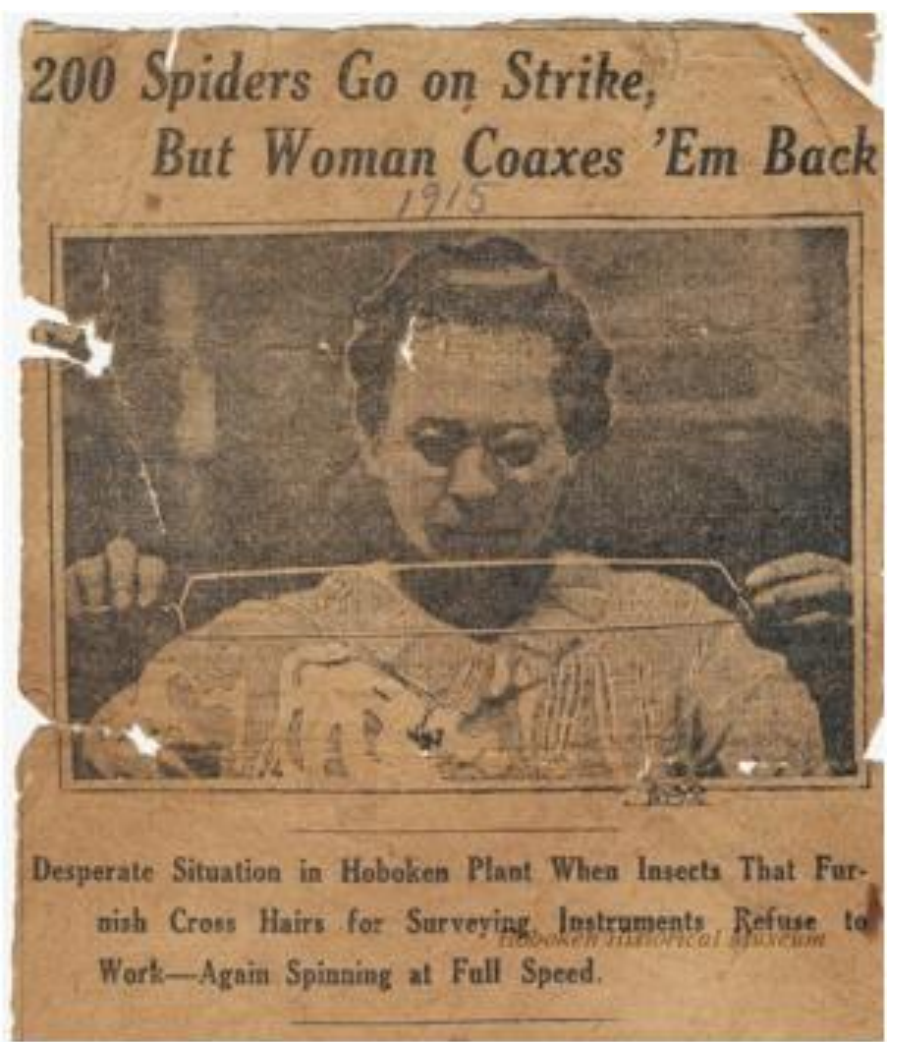

Fig. 9. Mary Pfeiffer, New York Evening Mail, [21 or 22] August 1915.

Credit: Hoboken Historical Museum, NJ

In the article Pfeiffer claims that the spiders began producing again once she tickled their feet.

In the 1930s, with the start of the Second World War, spider's silk became the standard material for crosshairs in military gunsights. To cope with the sudden demand for spider's silk, a number of spider farms were established in the United States. One of the most successful of these was that run in California by Nan Songer. 


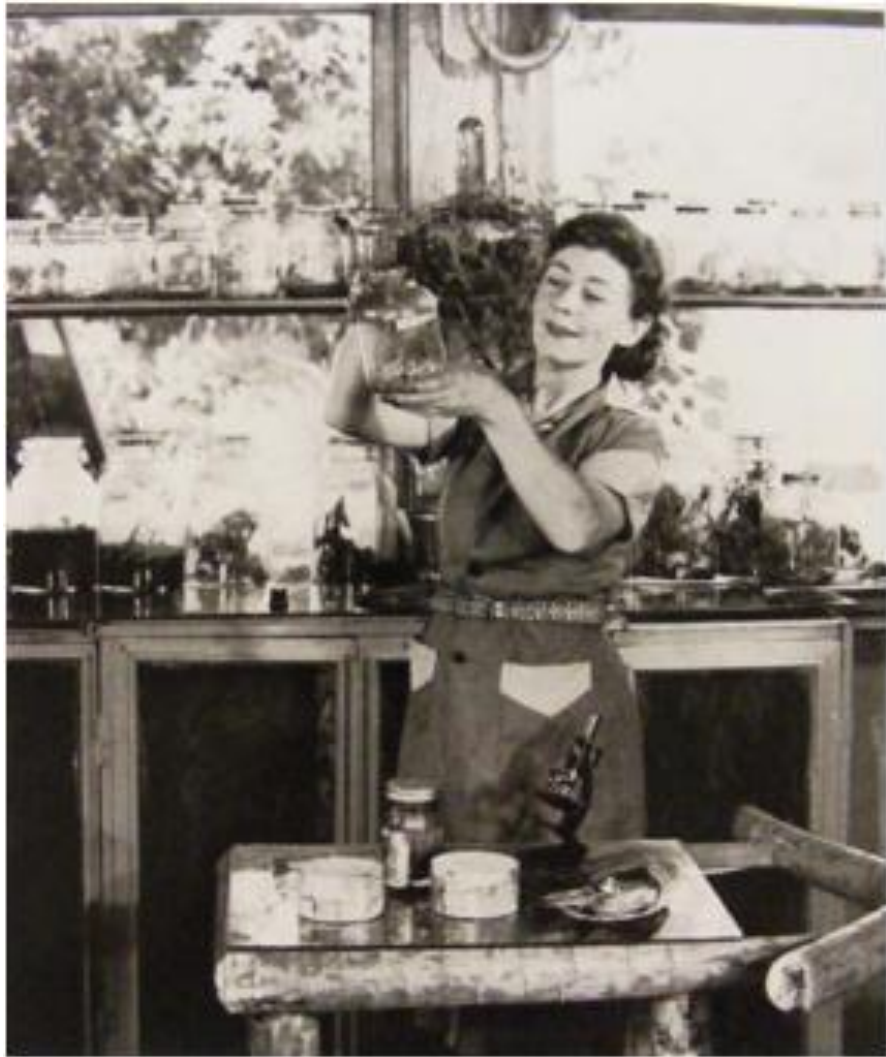

Fig. 10. Nan Songer in her sunroom in California.

(Nan Songer Hook, 'Spiders for Profit", Natural History Magazine

(November 1955), pp. 456-61 (p. 456). Credit: Paramount Pictures.

She collected spiders from her local area, and had up to 10,000 living in her house. Songer became so adept at collecting silk, and separating it into fine strands, that she was asked by the US National Bureau of Standards to provide a standardized list of spider's silk to specification. She produced a mail order catalogue with silk ranging from 'extra fine' to 'extra heavy'. For particularly fine instruments, she also offered the silk of newly hatched spiders that measured 500,000ths of an inch.

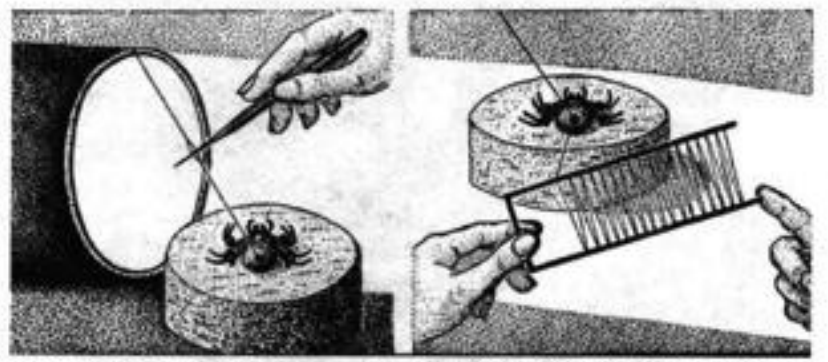

Fig. 11. Method for 'silking' spiders. Illustration by George Childs (Hook, 'Spiders for Profit', p. 459). Credit: Natural History Magazine.

This drawing depicts Songer's 'silking' technique. She stapled down the spider, and wound its silk on metal forks. Newspaper and journal articles of the time indicate that spiders were doing their bit for the war, 
and for business. They included such headlines as 'Black Widow Spiders Aid Sharpshooters'; 'Spiders For National Defence'; 'War-Working Spiders' and 'Spiders Spin For War'.

With its ability to withstand extremes of temperature and pressure, spider's silk was used in the sights of aeroplane bombers and in the periscopes of submarines - a machine that had first been used successfully in battle almost a century before, near the coast of Folly Island.

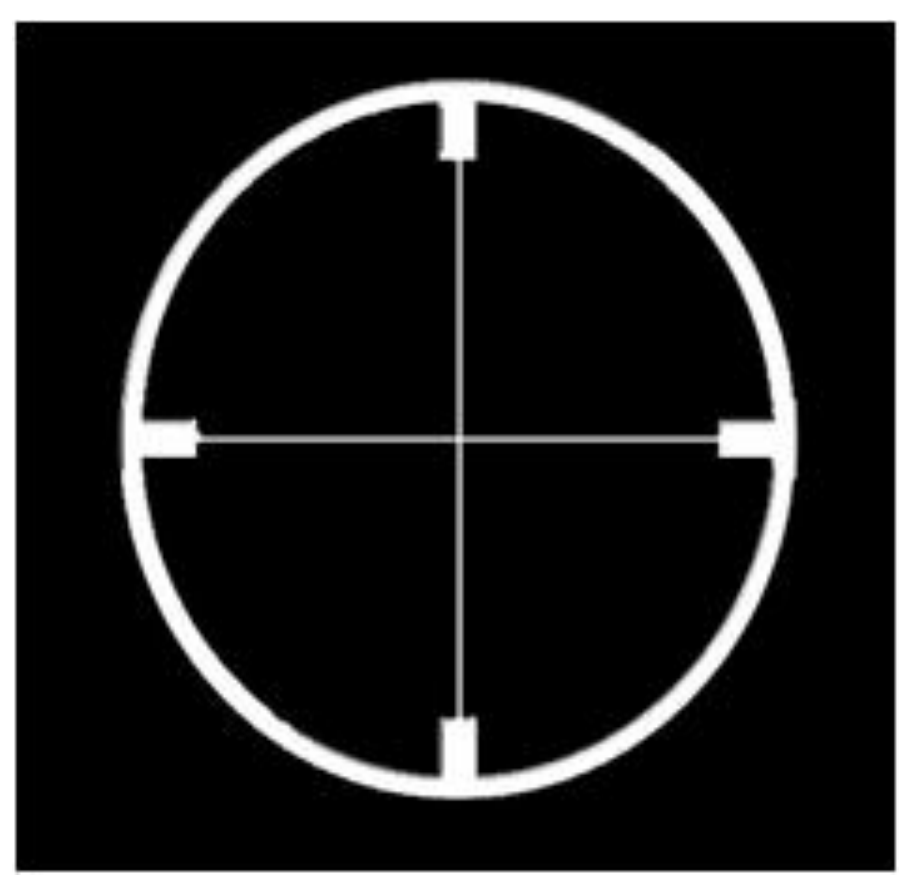

$A$ video of submarines is available in the HTML version of this article.

University College London

\section{Notes}

\footnotetext{
${ }^{1}$ Burt G. Wilder, 'How my new acquaintances spin', The Atlantic Monthly, 18 (1866): 132.

${ }^{2}$ For an in depth discussion of the history spider's silk cross hairs see Silvio Bedini, 'Along Came a Spider: Spinning Silk for Crosshairs, Part 1', The American Surveyor, 2.2 (March-April 2005).
}

\section{Works Cited}

Bedini, Silvio, 'Along Came a Spider: Spinning Silk for Crosshairs, Part 1', The American Surveyor, 2.2 (March-April 2005)

Songer Hook, Nan, 'Spiders for Profit', Natural History Magazine (November 1955), 456-61

Wilder, Burt G., 'How My New Acquaintances Spin', The Atlantic Monthly, 18 (1866), 132 